André de Lima Falcão

Classificação de Empresas Familiares de Acordo com a "Familiaridade"

Dissertação apresentada como requisito parcial para obtenção do título de Mestre pelo Programa de PósGraduação em Administração de Empresas da PUCRio.

Orientador: Prof. Jorge Ferreira da Silva 
André de Lima Falcão

\title{
Classificação de Empresas Familiares de Acordo com a
}

"Familiaridade"

\begin{abstract}
Dissertação apresentada como requisito parcial para obtenção do título de Mestre pelo Programa de PósGraduação em Administração de Empresas da PUC-Rio. Aprovada pela Comissão Examinadora abaixo assinada.
\end{abstract}

Prof. Jorge Ferreira da Silva Orientador Departamento de Administração - PUC Rio

Prof. Marcos Cohen Departamento de Administração - PUC Rio

Prof. Agrícola de Souza Bethlem COPPEAD - UFRJ

Prof. Nizar Messari Vice-Decano de Pós-Graduação do CCS

Rio de Janeiro, 07 de outubro de 2009 
Todos os direitos reservados. É proibida a reprodução total ou parcial do trabalho sem autorização da universidade, do autor e do orientador.

\section{André de Lima Falcão}

Graduou-se em Informática pelo Instituto de Matemática da UFRJ (Universidade Federal do Rio de Janeiro) em 2001. Tem interesse nas áreas de estratégia e organizações empresariais. Atuou de 1997 a 2006 nas mais diversas áreas de análise de sistemas. Atua desde 2006 como sócio de empresa na área de consultoria e educação em gestão empresarial.

Ficha Catalográfica

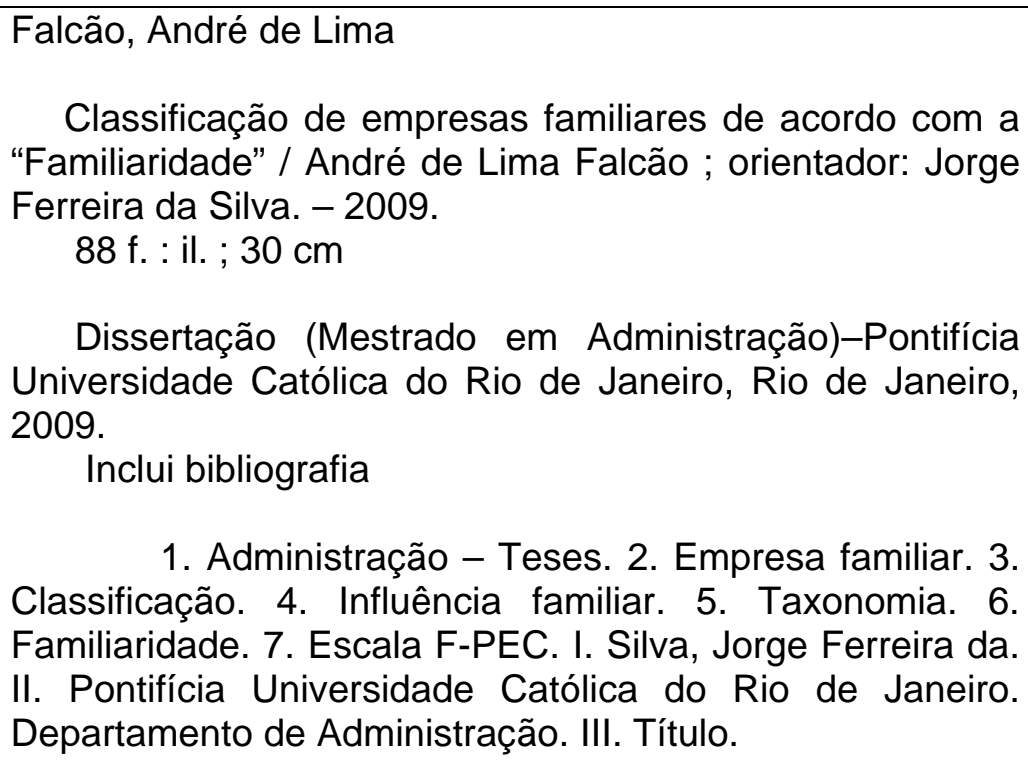

Classificação de empresas familiares de acordo com a "Familiaridade" / André de Lima Falcão ; orientador: Jorge Ferreira da Silva. - 2009.

88 f. : il. ; $30 \mathrm{~cm}$

Dissertação (Mestrado em Administração)-Pontifícia Universidade Católica do Rio de Janeiro, Rio de Janeiro, 2009.

Inclui bibliografia

1. Administração - Teses. 2. Empresa familiar. 3. Classificação. 4. Influência familiar. 5. Taxonomia. 6. Familiaridade. 7. Escala F-PEC. I. Silva, Jorge Ferreira da. II. Pontifícia Universidade Católica do Rio de Janeiro. Departamento de Administração. III. Título.

CDD: 658 
Para minha esposa Simone, por ser sempre minha inspiração e meu motivo de seguir adiante. 


\section{Agradecimentos}

Ao meu orientador Prof. Jorge Ferreira, por me estimular e me guiar na realização deste trabalho.

Aos professores Marcos Cohen e Agrícola Bethlem por abrilhantarem a banca.

Ao CNPq e à PUC-Rio, pelos auxílios concedidos, sem os quais este trabalho não poderia ter sido realizado.

À FBN-Brazil e IBGC, pela presteza em auxiliar na divulgação dos questionários. Aos meus colegas de mestrado, por compartilharem destes momentos importantes.

Aos amigos Anita, Ana Luiza e Bruno, que me apoiaram e compartilharam comigo seus e meus momentos de conquista.

A Leandro e Flávia, pela compreensão nos meus momentos de ausência da empresa e pela ajuda que sempre me deram.

A Ruy e Arlena, pela ajuda na pesquisa.

À Leila, pelo empenho na ajuda da coleta de dados.

A meus pais, pelo carinho e pela educação que me deram.

A meus sogros, pelo carinho e acolhimento de sempre.

À minha irmã Lilian, pela revisão.

Às minhas irmãs Lilian e Rachel, por serem sempre meus exemplos de dedicação aos estudos e competência.

Aos meus cunhados Robson e Diogo, pela ajuda e pelos importantes momentos de descontração.

À minha esposa Simone, por todo o carinho, amor, exemplo, incentivo e pela compreensão e ajuda que sempre me deu.

A Deus, por ter posto em minha vida pessoas tão maravilhosas. 


\section{Resumo}

Falcão, André de Lima. Silva, Jorge Ferreira. Classificação de Empresas Familiares de Acordo com a "Familiaridade". Rio de Janeiro, 2009. 88p. Dissertação de Mestrado - Departamento de Administração, Pontifícia Universidade Católica do Rio de Janeiro.

O presente estudo propõe uma taxonomia para empresas familiares e pretende contribuir para estimular o desenvolvimento das pesquisas nacionais nesse campo. Para isso, as empresas são agrupadas de acordo com o grau de interação e influência exercida pela família, ou familiness, através das dimensões Poder, Experiência e Cultura. Para realizar a pesquisa, utilizou-se uma adaptação da escala de influência familiar F-PEC (Familiness-Power, Experience, and Culture), introduzida por Astrachan, Klein e Smyrnios (2002), de onde foram extraídos os três constructos teóricos utilizados como as dimensões determinantes das classes desenvolvidas. Nesse sentido, as subescalas Poder, Experiência e Cultura formaram 27 possíveis classes, posteriormente buscadas na amostra, tendo em vista que elas medem a influência familiar no que diz respeito à propriedade, gestão, sucessão, dedicação e sinergia de valores empresa/família. Para isso, foram coletados dados a partir de um questionário respondido pelos principais membros diretores de empresas brasileiras consideradas familiares por seus respondentes. Em uma segunda etapa, a partir das variáveis da pesquisa, foi realizada uma análise estatística de fatores que confirma as dimensões teóricas e fortalece a ideia de que a escala F-PEC pode ser empregada na indústria brasileira. Em seguida, uma análise hierárquica de clusters apontou cinco grupos diferentes de empresas encontrados na amostra, confirmados na análise de K-means clusters. Diante dos dados, os resultados finais sugerem ser possível existir uma associação entre a quantidade de funcionários da empresa e o grupo ao qual pertence.

\section{Palavras-chave}

Empresa familiar; classificação; influência familiar; taxonomia; familiaridade; escala F-PEC. 


\section{Abstract}

Falcão, André de Lima. Silva, Jorge Ferreira (Advisor). Family Business Classification By Familiness; Rio de Janeiro, 2009; 88p; MSc. Dissertation -Departamento de Administração, Pontifícia Universidade Católica do Rio de Janeiro.

This study proposes a family business taxonomy and is intended to contribute stimulating the development of Brazilian researches in this field of knowledge. On that account, the firms are grouped by the degree of influence and interaction casted by the family, or familiness, through Power, Experience and Culture dimensions. To accomplish the research, has been used an adaptation of the F-PEC (Familiness-Power, Experience, and Culture) family influence scale, introduced by Astrachan, Klein e Smyrnios (2002), from where the three constructs has been extracted and used as dimensions of developed taxa. In this way, the Power, Experience and Culture subscales formed 27 possible taxa, searched in the sample afterward, since it measures the family influence by ownership, management, succession, dedication and synergy of firm/family values. On that account, data has been collected by a questionnaire answered by CEOs of Brazilian firms taken as family firms by then. In a second stage, a factor analysis has been executed from the research variables that assures the theoretical dimensions and strengthen the idea of the use of the F-PEC scale on Brazilian industry. Next, a hierarchical cluster analysis showed five different groups of firms found in the sample and confirmed by the K-Means cluster analysis. The final results suggests to be possible the existence of an association between the number of employees of the firm and the cluster it belongs.

\section{Keywords}

Family firm; family business; classification; family influence; taxonomy; familiness; F-PEC scale. 


\section{Sumário}

1 Introdução 14

$\begin{array}{ll}\text { 1.1. Objetivos } & 16\end{array}$

2 Definindo a Empresa Familiar $\quad 17$

3 A Escala F-PEC 20

3.1. Adequação da Escala à Definição Adotada 23

4 Taxonomia Sugerida $\quad 24$

5 Coleta de Dados $\quad 27$

6 Análise Estatística $\quad 32$

6.1. Dados Coletados 32

6.2. Tratamento dos Missing Values $\quad 35$

6.3. Teste de Normalidade 36

6.4. Transformação dos Valores $\quad 37$

6.5. Procura por Outliers 38

6.6. Análise de Fatores 39

6.7. Cálculo dos Fatores 43

6.8. Análise de Clusters 46

6.9. Método Hierárquico 47

6.10. Método K-Means 48

6.10.1. Seis Grupos 48

6.10.2. Cinco Grupos 50

6.10.3. Quatro Grupos 51

6.10.4. Quantidade Ideal 53

6.11. Interpretação dos Resultados 59

6.12. Comparação com Outras Variáveis 60 
7 Conclusões, Limitações e Sugestões 61

7.1. Considerações Finais 63

8 Referências Bibliográficas $\quad 65$

9 Apêndice A: Questionário $\quad 69$

10 Apêndice B: Tabelas 


\section{Lista de tabelas}

Tabela 1: Categorias da taxonomia proposta. 26

Tabela 2: Tabela de conversão para escala Likert. 28

Figura 4: Curva de experiência a cada sucessão. 30

Tabela 3: Escala de intenção de perpetuidade. 34

Tabela 4: Resultado do teste de normalidade executado no SPSS $® . \quad 36$

Tabela 5: Resultado da análise descritiva extraída do SPSS $®$. $\quad 37$

Tabela 6: Matriz de coeficientes da análise de fatores. 39

Figura 5: Gráfico scree plot da análise de fatores. 40

Tabela 7: Nova matriz de coeficientes da análise de fatores, excluindo-se a variável E4 41

Tabela 8: Resultados dos testes de Bartlett e MSA. 41

Tabela 9: Matriz de componentes do constructo Poder e

Resultados dos testes de Bartlett e MSA.

Tabela 10: Matriz de componentes do constructo Experiência e Resultados dos testes de Bartlett e MSA. 42

Tabela 11: Matriz de componentes do constructo Cultura e Resultados dos testes de Bartlett e MSA.

Tabela 12: Valores de cada variável latente formada pelos factor scores. 43

Tabela 13: Confiabilidade dos constructos.

Tabela 14: Testes de correlação entre as escalas semelhantes. $\quad 44$

Tabela 15: Valores das variáveis latentes gerados por

summated scales. $\quad 45$

Tabela 16: Distâncias quadradas de Mahalanobis. 46

Tabela 17: Coeficientes de aglomeração dos últimos estágios da análise hierárquica de clusters usando o método Between-groups. $\quad 47$

Tabela 18: Coeficientes de aglomeração dos últimos estágios da análise hierárquica de clusters usando o método Within groups. $\quad 47$

Tabela 19: Distâncias entre os seis centroides. 48

Tabela 20: Casos por grupo. 48 
Tabela 21: Posição dos seis centroides.

Tabela 22: Teste de MANOVA. $\quad 49$

Tabela 23: Distâncias entre os cinco centroides. 50

Tabela 24: Casos por grupo. 50

Tabela 25: Posição dos cinco centroides. 50

Tabela 26: Teste de MANOVA. 51

Tabela 27: Distâncias entre os quatro centroides. 51

Tabela 28: Casos por grupo. 51

Tabela 29: Posição dos quatro centroides. 51

Tabela 30: Teste de MANOVA. 52

Tabela 31: Análise descritiva das distâncias até o centro para seis grupos. 55

Tabela 32: Maiores distâncias encontradas.

Tabela 33: Análise descritiva das distâncias até o centro para cinco grupos. $\quad 56$

Tabela 34: Maiores distâncias encontradas. 56

Tabela 35: Análise descritiva das distâncias até o centro para quatro grupos. $\quad 57$

Tabela 36: Maiores distâncias encontradas.

Tabela 37: Coeficiente Eta para o Ano de Fundação e cluster

membership. 60

Tabela 38: Coeficiente Eta para o Quantidade de Funcionários e cluster membership. $\quad 60$

Tabela 39: Valores das variáveis coletadas. 73

Tabela 40: Valores das variáveis após o tratamento de missing values. 74

Tabela 41: Valores das transformadas z das variáveis. 75

Tabela 42: Valores extremos das variáveis. 80

Tabela 43: Dados coletados. 81 


\section{Lista de figuras}

Figura 1: Dimensões da Subescala Poder da escala F-PEC (Astrachan et al., 2002)

Figura 2: Dimensões da Subescala Experiência da escala F-PEC (Astrachan et al., 2002).

Figura 3: Dimensões da Subescala Cultura da escala F-PEC (Astrachan et al., 2002) 22

Figura 4: Curva de experiência a cada sucessão. 30

Figura 5: Gráfico scree plot da análise de fatores. 40 
As empresas familiares estão entre as mais eficientes locomotivas que impulsionam a economia local. Elas criam empregos; estão entre as poucas empresas com sucesso suficiente para pagar impostos; e demonstram agilidade e flexibilidade necessárias para manobrar com sucesso nas águas turbulentas da economia de suas nações.

Neubauer \& Lank (1998) 